\title{
Tensiometry as a Decision Tool for Abdominal Wall Reconstruction with Component Separation: Letter to the Editor
}

\author{
Uday S. Dadhwal
}

Published online: 15 October 2009

(C) Société Internationale de Chirurgie 2009

It was interesting to read about the use of tensiometry as a decision tool for abdominal wall reconstruction with component separation [1]. I want to bring to your notice, however, that the transverse view illustrated in Figure 1B shows but one rectus abdominis muscle. The other rectus abdominis is not shown, thereby making the diagram anatomically incorrect. So it is not possible to understand the depicted surgical repair as to how exactly the component separation is done for abdominal wall reconstruction. The procedure along with an accurate illustration is depicted in an earlier article published in the World Journal of Surgery [2].

\section{References}

1. Dragu A, Klein P, Unglaub F et al (2009) Tensiometry as a decision tool for abdominal wall reconstruction with component separation. World J Surg 33:1174-1180

2. de Vries Reilingh TS, van Goor H, Charbon JA et al (2007) Repair of giant midline abdominal wall hernias: "components separation technique" versus prosthetic repair. World J Surg 31:756-763

U. S. Dadhwal ( $₫)$

Department of Surgery, Armed Forces Medical College,

Pune 411040, Maharashtra, India

e-mail: usd999@rediffmail.com 